\title{
Multi-block Technique Applied to Navier-Stokes Equations in Two Dimensions
}

\section{Técnica Multi-Bloco Aplicada às Equações de Navier-Stokes em Duas Dimensões}

\author{
Jeferson Osmar de Almeida ${ }^{1}$; Diomar Cesar Lobão ${ }^{2}$; \\ Cleyton Senior Stampa ${ }^{3}$; Gustavo Benitez Alvarez ${ }^{4}$
}

\begin{abstract}
In this work, numerical solutions of the two-dimensional Navier-Stokes and Euler equations using explicit MacCormack method on multi-block structured mesh are presented for steady state and unsteady state compressible fluid flows. The multi-block technique and generalized coordinate system are used to develop a numerical solver which can be applied for a large range of compressible flow problems on complex geometries without modifying the governing equations and numerical method. Besides that the numerical method is based on a finite difference approach and the generalized coordinates introduced allow the application of the boundary conditions easily. The subsonic flow over a backward facing step and supersonic flow over a curved ramp are presented, and the results are compared with the experimental and numerical data.
\end{abstract}

Keywords: Navier-Stokes Equations. Generalized Coordinates. Multi-Block Structured Mesh. Explicit MacCormack Method. Finite Difference Method.

\section{Resumo}

Neste trabalho, soluções numéricas das equações bidimensionais de Navier-Stokes e Euler utilizando o método MacCormack em malha estruturada multi-block é apresentado para regime permanente e não permanente de escoamentos de fluidos compressíveis. A técnica multi-bloco e o sistema de coordenadas generalizadas são usados para desenvolver um solver que pode ser aplicado numa grande variedade de problemas de escoamentos compressíveis em geometrias complexas sem modificar as equações governantes e o método numérico. Além disso, o método numérico é baseado em diferenças finitas e as coordenadas generalizadas introduzidas permitem a aplicação facilmente das condições de contorno. $\mathrm{O}$ escoamento subsônico sobre um degrau descendente e o escoamento supersônico sobre uma rampa curva são apresentados e os resultados são comparados com dados experimentais e numéricos das referências.

Palavras-chave: Equações de Navier-Stokes. Coordenadas Generalizadas. Malha Estruturada Multi-Bloco. Método Explicito de MacCormack. Método de Diferenças Finitas.

\footnotetext{
${ }^{1}$ Me. em Modelagem Computacional em Ciência e Tecnologia, UFF, Volta Redonda, RJ, Brasil; E-mail: jefersonosmar@gmail.com

2 Dr. Prof. Depto. Ciências Exatas, UFF-EEIMVR, Volta Redonda, RJ, Brasil; E-mail: lobaodiomarcesar@yahoo.ca

${ }^{3}$ Dr. Prof. Depto. Engenharia Mecânica, UFF-EEIMVR, Volta Redonda, RJ, Brasil; E-mail: cleytonstampa@uol.com.br

${ }^{4}$ Dr. Prof. Depto. Ciências Exatas, UFF-EEIMVR, Volta Redonda, RJ, Brasil; E-mail: benitez.gustavo@gmail.com
} 


\section{Introduction}

Computational Fluid Dynamics (CFD) has become a powerful tool to analyze different problems that involves compressible fluid flows, such as for applications in the aerospace and defense industries. Currently, this computational tool is used to solve numerically the compressible Navier-Stokes equations, which are nonlinear partial differential equations that describe the flow in external and internal domains (ANDERSON; TANNEHILL; PLETCHER, 1984).

The main problem to obtain high accuracy in numerical solutions for problems of compressible fluid flow around complex geometries is the generation of mesh. This is an important procedure for fluid flow solved by numerical means because the generation of a quality mesh is crucial to the accuracy of numerical solutions and also convergence of the numerical methods.

As stated in (BAIRD; MCGUIRK, 1999) the development of a multi-block structured solver is quicker, has greater memory efficiency and has better geometry conformity than a single block code. The multi-block approach allows geometry to be altered easily with only the changed blocks requiring new mesh generation, reducing lead time for predictions of evolving geometry. Following the lead of (ZHANG; BLAISDELL; LYRINTZIS, 2004) other approach for the solution of the present problem is the use of high-order compact schemes with a high-order filter on multi-block domains. As discussed in (ALI et al., 2017) the search for optimal blocking methods for generating meshes suitable for flow simulations has been carried out using an adjoint-based error analysis of the meshes generated by these block topologies. It is found that, in general, the medial axis-based approaches provide optimal blocking and yields better accuracy in computing the functional of interest. In (THAKUR; WRIGHT, 2004) the authors make clear that the multiblock, non-orthogonal, body-fitted grids for very complex geometries is a key technique to enhancement of the solution for flow field in complex engineering applications such as unsteady rotorstator interactions in turbulent, all-speed turbo-machinery flows.

Several numerical methods are available for obtaining numerical solution of the governing equations of fluid dynamics, such as finite difference (FDM), finite element (FEM), and finite volume methods (FVM). However, in most engineering problems, numerical simulations of compressible fluid flow usually are performed in domains of complex geometries, where the finite difference methods are difficult to use, especially due to the application of the boundary conditions. Thus, the numerical grid generation, based on elliptic equations are used in order to discretize the domain. This make the grid lines to coincide with the boundary of the domain becoming much easer apply the boundary conditions (MALISKA, 1995; THOMPSON; WARSI; MASTIN, 1985). Furthermore, this system allows developing numerical codes that can be used to solve a large number of different problems without modifying the very core of the code (MALISKA, 1995; PULLIAM, 2005).

The usage of elliptic mesh generator with generalized coordinates some times do not yield in a convenient mesh. See below in figure 1 this specific situation. Around the corners of this warehouse shown, the mesh lines form a very distorted volumes which should be avoided. The multi-block idea comes in order to divide the domain in two meshes with a better quality of volumes close to the corners, as can be seen in figure 2 (ALMEIDA, 2015). The multi-block structured meshes are used to gives more control to refining the mesh locally and consequently improve the mesh quality without increasing the computational time and the memory requirements excessively (MALISKA, 1995; THOMPSON; WARSI; MASTIN, 1985; ERDOGAN, 2004).

Figure 1: Example of elliptic mesh generator with generalized coordinates.

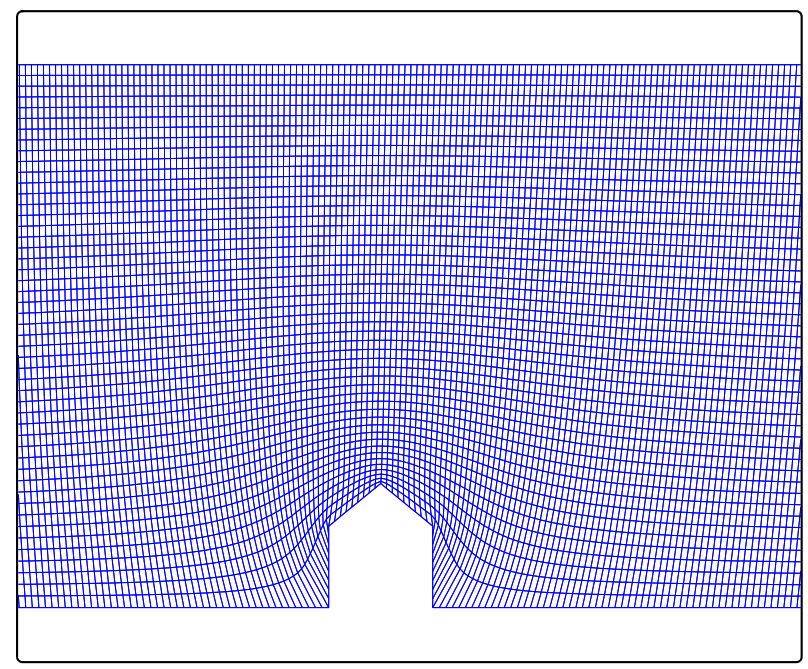

Source: The authors

In this work, numerical results are presented for transient and permanent compressible fluid flow in twodimensional geometries. The fully compressible NavierStokes and Euler equations are solved using explicit MacCormack method (MACCORMACK, 1969) for subsonic and supersonic flows. The classic second order finite difference when applied to the Navier-Stokes equation result in solution which revels typical oscillation near the discon- 
Figure 2: Example of elliptic mesh generator with generalized coordinates and multi-block idea.

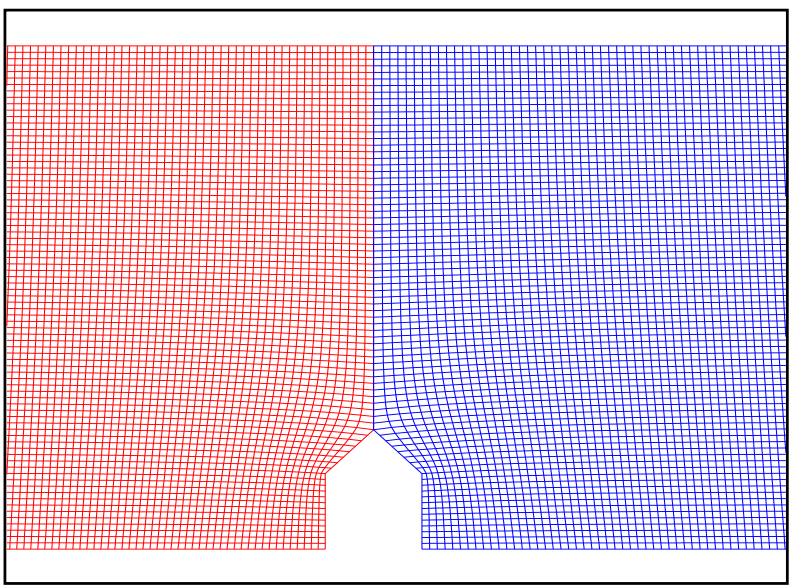

Source: The authors.

tinuity. The MacCormack (MACCORMACK, 1969) two steps numerical method is established in order to yield a better solution near the discontinuity even although do not eliminate such oscillations but attenuates them. So, the main advantage in use the two steps MacCormack method is in the easiness to implement it even with the multi-block domain discretization. The numerical solutions of two-dimensional subsonic laminar flow over a backward facing step and supersonic laminar flow over a curved ramp are compared with the results reported in the literature.

\section{Governing Equations}

The two-dimensional compressible Navier-Stokes equations in generalized coordinates system $(\xi, \eta)$ without body forces, mass diffusion, finite-rate chemical reactions, or external heat addition can be written in nondimensional conservative law form as (ANDERSON; TANNEHILL; PLETCHER, 1984)

$$
\frac{\partial \hat{\mathbf{Q}}}{\partial t}+\frac{\partial\left(\hat{\mathbf{E}}_{i n v}-\hat{\mathbf{E}}_{v i s}\right)}{\partial \xi}+\frac{\partial\left(\hat{\mathbf{F}}_{i n v}-\hat{\mathbf{F}}_{v i s}\right)}{\partial \eta}=0,
$$

where $\hat{\mathbf{Q}}$ is the state vector of conservative variables defined by

$$
\hat{\mathbf{Q}}=\left[\begin{array}{c}
\rho \\
\rho U \\
\rho V \\
E_{t}
\end{array}\right]
$$

$\hat{\mathbf{E}}_{i n v}$ and $\hat{\mathbf{F}}_{i n v}$ are the inviscid flux vectors, and $\hat{\mathbf{E}}_{v i s}$ and $\hat{\mathbf{F}}_{v i s}$ are the viscous flux vectors in the $\xi$ and $\eta$ directions, which are given below

$$
\begin{gathered}
\hat{\mathbf{E}}_{i n v}=J^{-1}\left[\begin{array}{c}
\rho U \\
\rho u U+\xi_{x} p \\
\rho \nu U+\xi_{y} p \\
\left(E_{t}+p\right) U
\end{array}\right], \\
\hat{\mathbf{F}}_{i n v}=J^{-1}\left[\begin{array}{c}
\rho V \\
\rho u V+\eta_{x} p \\
\rho \nu V+\eta_{y} p \\
\left(E_{t}+p\right) V
\end{array}\right],
\end{gathered}
$$

$$
\hat{\mathbf{E}}_{v i s}=J^{-1}\left[\begin{array}{c}
0 \\
\operatorname{Re}^{-1}\left(\xi_{x} \tau_{x x}+\xi_{y} \tau_{x y}\right) \\
\operatorname{Re}^{-1}\left(\xi_{x} \tau_{x y}+\xi_{y} \tau_{y y}\right) \\
\operatorname{Re}^{-1}\left(\xi_{x} \beta_{x}+\xi_{y} \beta_{y}\right)
\end{array}\right]
$$

$$
\hat{\mathbf{F}}_{v i s}=J^{-1}\left[\begin{array}{c}
0 \\
\operatorname{Re}^{-1}\left(\eta_{x} \tau_{x x}+\eta_{y} \tau_{x y}\right) \\
\operatorname{Re}^{-1}\left(\eta_{x} \tau_{x y}+\eta_{y} \tau_{y y}\right) \\
\operatorname{Re}^{-1}\left(\eta_{x} \beta_{x}+\eta_{y} \beta_{y}\right)
\end{array}\right]
$$

where $J$ is the Jacobian of the transformation, $\rho$ is the density, $u$ and $v$ are the velocity components in the $\xi$ and $\eta$ coordinate directions, $U$ and $V$ are the contravariant velocities, $E_{t}$ is total energy per unit of volume, $\xi_{x}, \xi_{y}$, $\eta_{x}$ and $\eta_{y}$ are the metrics of transformation, $\beta_{x}=\tau_{x x} u+$ $\tau_{x y} v$ and $\beta_{y}=\tau_{x y} u+\tau_{y y} v, p$ is the static pressure and $\tau$ describes the stress components for viscous flow.

The Navier-Stokes equations are based on the universal law of conservation of mass, conservation of momentum and conservation of energy. However, to complete this system of equations is necessary to add an equation of state that can be written as (ANDERSON; TANNEHILL; PLETCHER, 1984)

$$
p=(\gamma-1)\left(E_{t}-\frac{1}{2} \rho\left(u^{2}+v^{2}\right)\right)
$$

in which the fluid is considered a perfect gas. In the above equation (7), $\gamma$ denotes the ratio of the specific heats. 
The dimensionless of the variables is performed to eliminate the scale problems and are dimensionless as follows (ANDERSON; TANNEHILL; PLETCHER, 1984),

$$
\begin{gathered}
t^{*}=\frac{t u_{\infty}}{l_{\infty}}, \\
\rho^{*}=\frac{\rho}{\rho_{\infty}}, \\
u^{*}=\frac{u}{u_{\infty}}, \\
v^{*}=\frac{v}{u_{\infty}}, \\
E_{t}^{*}=\frac{E_{t}}{\rho_{\infty} u_{\infty}^{2}} . \\
p^{*}=\frac{p}{\rho_{\infty} u_{\infty}^{2}},
\end{gathered}
$$

In these expressions as described before, the sub indexes $\infty$ refers to the free stream flow and the upper index $*$ refers to the dimensionless variables (one could use stagnation state in place of free stream). For simplicity the development of the govern equations, the upper index $*$ will be discarded, because such equations are invariant to these transformations (ANDERSON; TANNEHILL; PLETCHER, 1984).

The Reynolds number and Mach number are defined as $R e=\frac{\rho_{\infty} u_{\infty} l_{0}}{\mu_{\infty}}$ and $M=\frac{u_{\infty}}{a_{\infty}}$, respectively, where $a_{\infty}$ is the speed of sound of an ideal gas, $l_{0}$ is a characteristic length of the domain, and $\mu$ is the coefficient of dynamic viscosity. The free-stream conditions are denoted by the infinite symbol.

The compressible Euler equations describe the inviscid compressible flow. This system of equations can be obtained by neglecting the viscous terms from the equation (1).

\section{Numerical Method}

The MacCormack method (MACCORMACK, 1969) is used for solving the governing equations as given by equation (1). The numerical method is an explicit predictor-corrector scheme based on a finite difference formulation that has been used for compressible flow, and it has second-order of accuracy in both space and time.

When the method is applied to the two-dimensional compressible Navier-Stokes equations given by (1), it can be written as (ANDERSON; TANNEHILL; PLETCHER, 1984; MACCORMACK, 1969)

Predictor:

$$
\begin{aligned}
\hat{\mathbf{Q}}_{i, j}^{\overline{n+1}}=\hat{\mathbf{Q}}_{i, j}^{n} & -\frac{\Delta t}{\Delta \xi}\left[(\hat{\mathbf{E}})_{i+1, j}^{n}-(\hat{\mathbf{E}})_{i, j}^{n}\right] \\
& -\frac{\Delta t}{\Delta \eta}\left[(\hat{\mathbf{F}})_{i, j+1}^{n}-(\hat{\mathbf{F}})_{i, j}^{n}\right],
\end{aligned}
$$

\section{Corrector:}

$$
\begin{aligned}
& \hat{\mathbf{Q}}_{i, j}^{n+1}=\frac{1}{2}\left[\hat{\mathbf{Q}}_{i, j}^{n}+\hat{\mathbf{Q}}_{i, j}^{\overline{n+1}}-\frac{\Delta t}{\Delta \xi}\left((\hat{\mathbf{E}})_{i, j}^{\overline{n+1}}-(\hat{\mathbf{E}})_{i-1, j}^{\overline{n+1}}\right)\right. \\
& \left.\left.-\frac{\Delta t}{\Delta \eta}\left((\hat{\mathbf{F}})_{i, j}^{\overline{n+1}}-(\hat{\mathbf{F}})_{i, j-1}^{\overline{n+1}}\right)\right)\right],
\end{aligned}
$$

where $\hat{\mathbf{E}}=\hat{\mathbf{E}}_{i n v}-\hat{\mathbf{E}}_{v i s}$ and $\hat{\mathbf{F}}=\hat{\mathbf{F}}_{i n v}-\hat{\mathbf{F}}_{v i s}$. The explicit MacCormack method requires the predictor be calculated first to $n=0$ (initial conditions), so the primitive variables are obtained from the $\hat{\mathbf{Q}}^{\overline{n+1}}$ vector by (14). Then the corrector step is finally calculated for the state vector given by $\hat{\mathbf{Q}}^{n+1}$ in (15). So the entire process goes on to $n=1,2, \ldots$

As stated by Roe (ROE, 1981) any flow which goes through Mach 1.0, the classical numerical methods (Finite Difference/Finite Volume) present physical discontinuities, so needs special numerical treatment. In the present work the flow is much greater than Mach 1.0, well developed supersonic flow. In this case the MacCormack method does not require such special treatment. Note that MacCormick method does not carry any special treatment for the convective terms (inviscid) or any other terms in the formulation, it is a very naive method.

In this work, the boundary conditions are defined as follows: inflow, outflow and lower and upper solid wall. The inflow condition, all variables are prescribed as Dirichlet boundary conditions in supersonic regime. For outflow condition, with subsonic flow, the value of the static pressure $p$ is prescribed as Dirichlet boundary conditions and all other variables are extrapolated, but if the flow is supersonic, all other variables are extrapolated. The solid wall condition are represented by non-slip boundary condition $u=0$ for viscous flow and free-slip boundary condition $U \cdot \mathbf{n}=0$ for inviscid flow, where in the last case the velocity components are calculated through of the contravariant velocity components. However, in both cases all other variables are extrapolated. 


\section{Boundary Conditions}

The Dirichlet boundary condition is one of the easiest

or by, to use and implemented computationally. For the computational codes in compressible fluid flow, they can be of the type:

- (Inlet): It is the region where the injection of fluid occurs in the domain, where all properties are provided.

- (Outlet): It is the region that represents the output of the fluid in the domain. The boundary conditions are approximated by extrapolation as follows:

$$
\begin{gathered}
\rho_{i, j}=\frac{4 \rho_{i-1, j}-\rho_{i-2, j}}{3}, \\
u_{i, j}=\frac{4 u_{i-1, j}-u_{i-2, j}}{3}, \\
v_{i, j}=\frac{4 v_{i-1, j}-v_{i-2, j}}{3}, \\
p_{i, j}=\frac{4 p_{i-1, j}-p_{i-2, j}}{3} .
\end{gathered}
$$

With this, one can determine the total energy:

$$
\left(E_{t}\right)_{i, j}=\frac{p_{i, j}}{(\gamma-1)}+\frac{1}{2} \rho_{i, j}\left(v_{i, j}^{2}+u_{i, j}^{2}\right) .
$$

- (Opening): These boundary conditions allow the fluid flow from inside towards the outside the domain, depending only on the flow conditions. The boundary conditions can be determined according to the following expressions:

$$
\begin{aligned}
& \rho_{i, j}=\frac{4 \rho_{i, j-1}-\rho_{i, j-2}}{3}, \\
& u_{i, j}=\frac{4 u_{i, j-1}-u_{i, j-2}}{3}, \\
& v_{i, j}=\frac{4 v_{i, j-1}-v_{i, j-2}}{3}, \\
& p_{i, j}=\frac{4 p_{i, j-1}-p_{i, j-2}}{3},
\end{aligned}
$$

$$
\rho_{i, j}=\frac{4 \rho_{i, j+1}-\rho_{i, j+2}}{3}
$$

$$
u_{i, j}=\frac{4 u_{i, j+1}-u_{i, j+2}}{3}
$$

$$
v_{i, j}=\frac{4 v_{i, j+1}-v_{i, j+2}}{3},
$$

$$
p_{i, j}=\frac{4 p_{i, j+1}-p_{i, j+2}}{3} .
$$

With this, the internal energy can be determined according to equation (20).

- (Solid Wall): Represents the solid boundary conditions of viscous and non-viscous flow. For density, pressure and energy, the boundary conditions can be determined according to the conditions of type Opening. However, the application of the boundary conditions to the velocity is different, being classified as Free-Slip for non-viscous flow and No-Slip for viscous flow.

For the boundary condition of type Free-Slip, the velocity on the wall is not zero and can be determined by the following relationships.

\section{Contravariant Velocity $V$ :}

$$
\left|\eta_{x}\right| \geq\left|\eta_{y}\right| \Rightarrow\left\{\begin{array}{l}
v=\left(4 v_{i, j+1}-v_{i, j+2}\right) / 3 \\
u=-\eta_{y} v / \eta_{x}
\end{array},\right.
$$

$$
\left|\eta_{x}\right|<\left|\eta_{y}\right| \Rightarrow\left\{\begin{array}{l}
u=\left(4 u_{i, j+1}-u_{i, j+2}\right) / 3 \\
v=-\eta_{x} u / \eta_{y}
\end{array},\right.
$$

or by,

$$
\left|\eta_{x}\right| \geq\left|\eta_{y}\right| \Rightarrow\left\{\begin{array}{l}
v=\left(4 v_{i, j-1}-v_{i, j-2}\right) / 3 \\
u=-\eta_{y} v / \eta_{x}
\end{array},\right.
$$

$$
\left|\eta_{x}\right|<\left|\eta_{y}\right| \Rightarrow\left\{\begin{array}{l}
u=\left(4 u_{i, j-1}-u_{i, j-2}\right) / 3 \\
v=-\eta_{x} u / \eta_{y}
\end{array} .\right.
$$


2. Contravariant Velocity $U$ :

$$
\left|\xi_{x}\right| \geq\left|\xi_{y}\right| \Rightarrow\left\{\begin{array}{l}
v=\left(4 v_{i-1, j}-v_{i-2, j}\right) / 3 \\
u=-\xi_{y} v / \xi_{x}
\end{array}\right.
$$

$$
\left|\xi_{x}\right|<\left|\xi_{y}\right| \Rightarrow\left\{\begin{array}{l}
u=\left(4 u_{i-1, j}-u_{i-2, j}\right) / 3 \\
v=-\xi_{x} u / \xi_{y}
\end{array},\right.
$$

or by,

$$
\begin{gathered}
\left|\xi_{x}\right| \geq\left|\xi_{y}\right| \Rightarrow\left\{\begin{array}{l}
v=\left(4 v_{i+1, j}-v_{i+2, j}\right) / 3 \\
u=-\xi_{y} v / \xi_{x}
\end{array},\right. \\
\left|\xi_{x}\right|<\left|\xi_{y}\right| \Rightarrow\left\{\begin{array}{l}
u=\left(4 u_{i+1, j}-u_{i+2, j}\right) / 3 \\
v=-\xi_{x} u / \xi_{y}
\end{array} .\right.
\end{gathered}
$$

In the case of No-Slip boundary condition, the velocity on the wall is zero according to the boundary layer concept of the viscous flow.

The implementation of the multi-block solver is realized dividing the domain into subdomains (blocks), where the mesh of each block is generated separately. The governing equations are solved in each block independently, but as the interfaces of each one are connected properly, the communication with each other are realized and, therefore, the physics of the problem is conserved (MALISKA, 1995; ERDOGAN, 2004).

\section{Block Interface}

A multi-block structured mesh with two blocks is used to clarify the block interface boundary condition treatment, as shown partially in figure 3 . The first block, which is in red, is where the fluid enters. The second block, which is in blue, is where the fluid from block 1 becomes its inlet. The mesh of each block has $60 \times 50$ nodes.

Figure 3: View at the interface of two blocks.

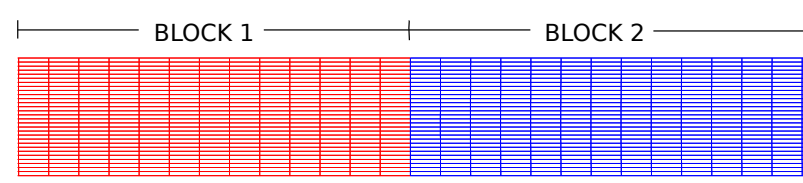

Source: The authors.
For the treatment of the boundary between blocks 1 and 2 , it is observed that they are physically coincident. For the exchange of information between the blocks, the multi-block structured mesh is coincident at the boundary.

At the boundary between the blocks, the boundary of block 1 is considered as an outflow boundary condition, since the fluid leaves this block. In block 2 , the boundary is the inlet of the fluid exiting block 1 , being considered an inlet boundary condition. As can be seen in figure 4, the values of the input variables of block 2 are equal to the values of the output variables of block 1 .

Figure 4: View of boundary interface connection.

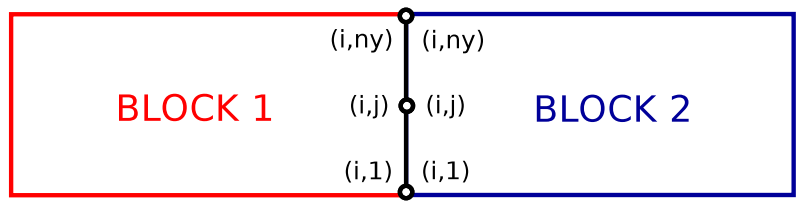

Source: The authors.

Analyzing the figure 4 , it is observed that the vector of conserved variables $\hat{\mathbf{Q}}$ is coincident at the boundary for blocks 1 and 2, where

$$
\hat{\mathbf{Q}}_{B 1}=\hat{\mathbf{Q}}_{B 2}
$$

In order to avoid a numerical discontinuity of the solution at the boundary between the blocks, after each iteration a numerical boundary condition is applied at this border, where the values of the variables are determined through the variables neighboring of such boundary.

This numerical condition is applied to the flow variables according to the following expressions:

$$
\begin{gathered}
\widetilde{\rho}_{i, j}=\frac{\rho_{i-1, j}+\rho_{i+1, j}}{2}, \\
\widetilde{u}_{i, j}=\frac{u_{i-1, j}+u_{i+1, j}}{2},
\end{gathered}
$$

$$
\widetilde{v}_{i, j}=\frac{v_{i-1, j}+v_{i+1, j}}{2},
$$

$$
\widetilde{p}_{i, j}=\frac{p_{i-1, j}+p_{i+1, j}}{2},
$$




$$
\left(\widetilde{E}_{t}\right)_{i, j}=\frac{\widetilde{p}_{i, j}}{(\gamma-1)}+\frac{1}{2} \widetilde{\rho}_{i, j}\left(\widetilde{v}_{i, j}^{2}+\widetilde{u}_{i, j}^{2}\right)
$$

With the input and initial conditions and the boundary conditions mentioned above, it is possible to obtain satisfactory numerical results by implementing the MacCormack original method (MACCORMACK, 1969) and the use of multi-block structured mesh in the cases discussed as follow.

The monitoring of the stability of the numerical scheme is performed by observing the residue at all internal points of the discretized domain, according to the equation below

$$
\text { residue }=\log _{10}\left[\sum_{i, j=2,2}^{M-1, N-1} \sqrt{\frac{J^{2}\left(\hat{\mathbf{Q}}_{i, j}^{n-1}-\hat{\mathbf{Q}}_{i, j}^{n}\right)^{2}}{(M-2)(N-2)}}\right] \text {. }
$$

Among the conserved variables of $\hat{\mathbf{Q}}$, the one used in the above equation for determining the residue is the density $\rho$.

To keep the numerical scheme stable, the value of the time integration step can be defined by the following empirical formula in generalized coordinates (ANDERSON; TANNEHILL; PLETCHER, 1984; MACCORMACK, 1969; PEYRET; TAYLOR, 1983)

$$
\Delta t=\frac{C F L}{\left(\frac{2 v}{R e}+C F x+C F y\right)},
$$

where $C F L$ is the Courant-Friedrichs-Lewy number. For the explicit MacCormack scheme the $C F L$ must be less than or equal to 0.5 . The values of $C F x$ and $C F y$ for the above equation can be determined through the following expressions:

$$
\begin{aligned}
& C F x=\left|\xi_{x} u+\xi_{y} v\right|+\sqrt{\frac{\gamma p}{\rho}} \sqrt{\xi_{x}^{2}+\xi_{y}^{2}}, \\
& C F y=\left|\eta_{x} u+\eta_{y} v\right|+\sqrt{\frac{\gamma p}{\rho}} \sqrt{\eta_{x}^{2}+\eta_{y}^{2}},
\end{aligned}
$$

where $C F x$ and $C F y$ are maximum values in the domain.

\section{Numerical Results}

The capabilities of the methodology adopted in this work are demonstrated by numerical simulation over two test cases.

\section{Flow Over a Backward-facing Step}

The first test is the well known subsonic flow over a backward facing step that is often used as benchmark problem in computational fluid dynamics. The main feature of this flow is that it has a simple geometry that generates an interesting and complex flow field, such as flow separation, reattachment zone and recirculation bubbles on the upper and lower wall of the channel. These characteristics are dependent on the Reynolds number and the geometrical parameters (ARMALY et al., 1983; BISWAS; BREUER; DURST, 2004; SALEEL; SHAIJA; JAYARAJ, 2013).

For the numerical simulations, the following initial conditions are assumed: density $\rho_{0}=1.21 \mathrm{~kg} / \mathrm{m}^{3}$, pressure $p_{0}=1.01 \times 10^{5} \mathrm{~N} / \mathrm{m}^{2}$, coefficient of dynamic viscosity $\mu=1.81 \times 10^{-5} \mathrm{~kg} /(\mathrm{m} . \mathrm{s})$, and ratio of the specific heats $\gamma=1.4$. The mesh used in the multi-block solution of this problem is shown in figure 5. The block 1 (upstream block) has a mesh size of $25 \times 25$ and the block 2 (downstream block) has size of $160 \times 50$.

Figure 5: Mesh of two blocks of backward-facing step.

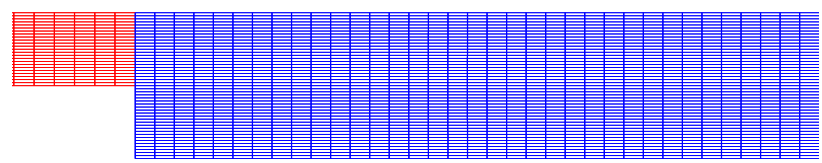

Source: The authors.

The figures 6 and 7 shows the velocity contours of the steady state flow field for two different Reynolds number ( $R e=50$ and 100) for expansion ratio $H / h=1.9423(\approx 2)$. In all cases shown in figures, a vortex is found in the concave corner behind the step and the maximum velocity is located on the upstream side of the channel, as found in the experiments performed by (ARMALY et al., 1983; BISWAS; BREUER; DURST, 2004; SALEEL; SHAIJA; JAYARAJ, 2013). It can also be seen that the size of the recirculation region increases with increasing Reynolds number.

The Table 1 describes the variation of reattachment length $\left(x_{r}\right)$ for two different Reynolds numbers $(R e=50$ and 100), which clearly shows that the reattachment length increase with increasing Reynolds number, as found in the references. In the second column are presented expe- 
rimental values obtained in (ARMALY et al., 1983), and denoted by REF-1. The third column presents the results obtained in this work, and denoted by Authors. The fourth and fifth columns correspond to values obtained by numerical simulations in (BISWAS; BREUER; DURST, 2004) and (SALEEL; SHAIJA; JAYARAJ, 2013), and denoted by REF-2 and REF-3 respectively.

Figure 6: Velocity contours for flow over a backwardfacing step with $R e=50$.

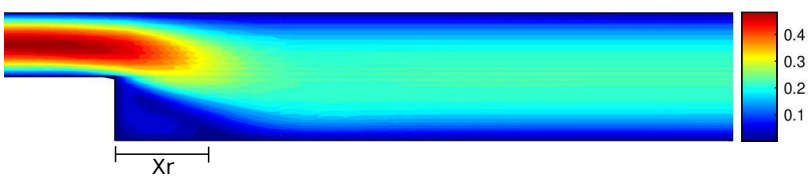

Source: The authors.

Figure 7: Velocity contours for flow over a backwardfacing step with $R e=100$.

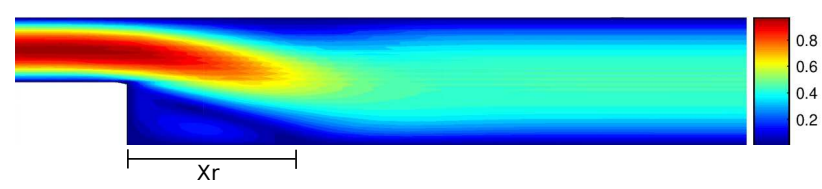

Source: The authors.

Table 1: Comparation of the results for flow over a backwardfacing step.

\begin{tabular}{ccccc}
\hline & Experimental $x_{r}$ & \multicolumn{3}{c}{ Numerical $x_{r}$} \\
\cline { 2 - 5 } $\operatorname{Re}$ & REF-1 & Authors & REF-2 & REF-3 \\
\hline 50 & 1.70 & 1.61 & 1.55 & 1.55 \\
100 & 3.06 & 2.82 & 2.80 & 2.81 \\
\hline
\end{tabular}

The results obtained by the present work are quite compatible with results found in the references. As can be clearly seen in figures 6 and 7 and Table 1, the results are in agreement with the numerical data of (BISWAS; BREUER; DURST, 2004; SALEEL; SHAIJA; JAYARAJ, 2013), especially with respect to the reattachment length.

\section{Flow Over a Curved Ramp}

The second test case is a transient supersonic flow over a curved ramp at Mach number 1.5 that can be used as benchmark problem for the supersonic Euler equations. This flow is characterized by the formation of a detached bow shock in front of the curved ramp and of an expansion wave. Moreover, other feature is the wave shock reflection from the solid wall (LOBAO, 2010; LOBAO, 1992; ALLEN, 1992).

For the numerical simulation, the initial conditions are as follows: density $\rho_{0}=1.21 \mathrm{~kg} / \mathrm{m}^{3}$, pressure $p_{0}=$ $1.01 \times 10^{5} \mathrm{~N} / \mathrm{m}^{2}$, and ratio of the specific heats $\gamma=1.4$. The mesh for the multi-block solutions of this problem is given in figure 8 . The mesh sizes in the first and second blocks are $110 \times 80$ and $60 \times 80$, respectively.

Figure 8: Mesh of two blocks of curved ramp.

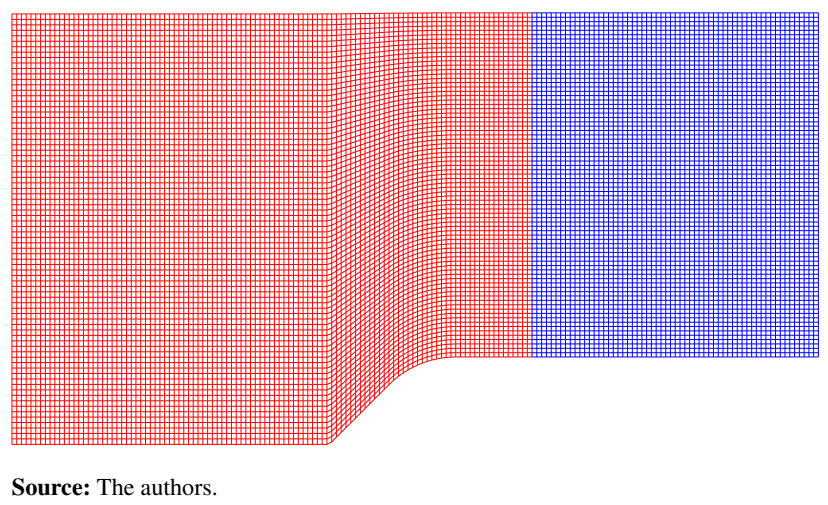

The pressure and Mach number contour over a curved ramp are shown in figures 9 and 10, respectively, for Mach number 1.5. The detached bow shock in front of the curved ramp can be seen in the figures as well as the shock reflection from the solid wall. The figure 10 shows the expansion wave, where is possible to observe the subsonic, transonic and supersonic zones before of the curved ramp. As can be observed in figures 9 and 10 there is no spurious oscillation at the interface boundary between the two blocks even in presence of a very strong shock wave structure. The numerical interface boundary condition is well suited for this simulation which demonstrates its applicability.

Figure 9: Pressure contour over a curved ramp.

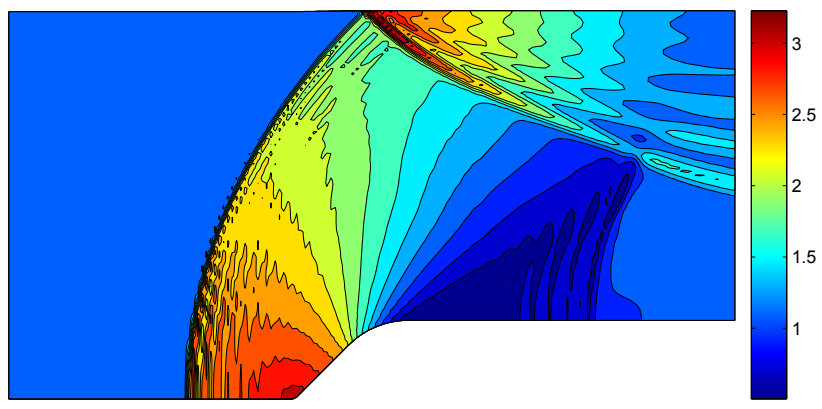

Source: The authors. 
Figure 10: Mach number contour over a curved ramp.

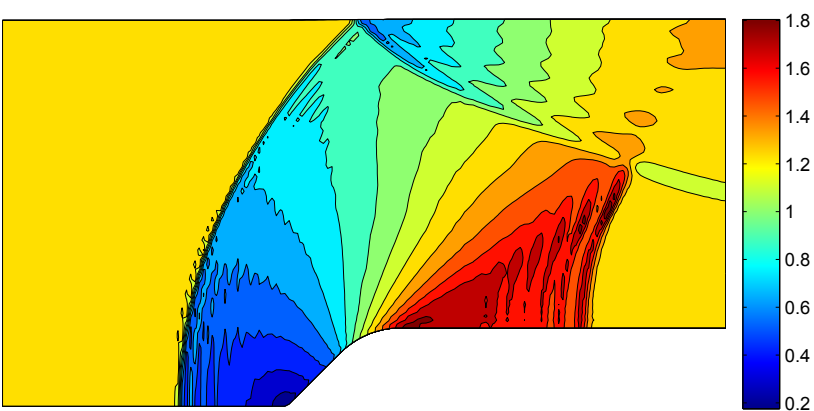

Source: The authors

The present numerical results are compared with the numerical data presented in (LOBAO, 2010). The two results are in good agreement.

\section{Conclusions}

In this work, the discretization of the Navier-Stokes and Euler equations on multi-block structured mesh is realized using explicit MacCormack method. The numerical results for steady state and unsteady state compressible fluid flow in two-dimensional geometries are presented for two different test cases in subsonic and supersonic regimes, the flow over a backward facing step and flow over a curved ramp, respectively, which indicated good agreement with the references data. Therefore, it is shown the capability of the methodology to obtain numerical results for these types of subsonic and supersonic flows in two-dimensional complex geometries.

\section{Acknowledgements}

This study was financed in part by the Fluminense Federal University and the Coordenação de Aperfeiçoamento de Pessoal de Nível Superior - Brasil (CAPES) Finance Code 001.

\section{References}

ALI, Z.; DHANASEKARAN, P.; TUCKER, P.; WATSON, R.; SHAHPAR, S. Optimal multi-block mesh generation for cfd. International Journal of Computational Fluid Dynamics, 2017. v. 31, p. 195-213, 2017.

ALLEN, C. An Efficient Euler Solver for Predominantly Supersonic Flows with Embedded Subsonic Pockets. Tese (PhD thesis) - University of Bristol, 1992.
ALMEIDA, J. Solução Numérica por Diferenças Finitas em Malha Estruturada Multibloco das Equações de Navier-Stokes para Escoamento Compressivel. Dissertação (Master's thesis) - Universidade Federal Fluminense, 2015.

ANDERSON, D.; TANNEHILL, J.; PLETCHER, R. Computational fluid mechanics and heat transfer. In: . [S.1.]: Hemisphere Publishing Corporation - McGraw Hill, 1984.

ARMALY, B.; DURST, F.; PEREIRA, J.; SCHONUNG, B. Experimental and theoretical investigation of backwardfacing step flow. J. Fluid Mech, 1983. v. 127, p. 473-496, 1983.

BAIRD, S.; MCGUIRK, J. J. Multi-block parallel simulation of fluid flow in a fuel cell. In: High-Performance Computing and Networking. HPCN-Europe 1999. [S.1.]: Springer Lecture Notes in Computer Science, 1999. v. 1583 , p. $1042-1051$.

BISWAS, G.; BREUER, M.; DURST, F. Backward-facing step flows for various expansion ratios at low and moderate reynolds numbers. Journal of Fluids Engineering, 2004. v. 126, p. 362-374, 2004. DOI: 10.1115/1.1760532.

ERDOGAN, E. Development of a Navier-Stokes for Multiblock Applications. Dissertação (Master's thesis) — Middle East Technical University, 2004.

LOBAO, D. High Resolution Schemes Applied to the Euler Equations. Tese (PhD thesis) - University of Bristol, 1992.

LOBAO, D. Numerical simulations of navier-stokes for transient flows in 2d. In: Mecanica Computacional. Buenos Aires, Argentina: [s.n.], 2010. XXIX, p. 36013611.

MACCORMACK, $\mathrm{R}$. The effect of viscosity in hypervelocity impact cratering. AIAA., 1969. p. 69-354, 1969.

MALISKA, C. Transferencia de calor e mecanica dos fluidos computacional. In: . [S.1.]: LTC, 1995.

PEYRET, R.; TAYLOR, T. Computational methods for fluid flow. In: Springer Series in Computational Physics. 1. ed. [S.1.]: Springer, 1983.

PULLIAM, T. Solution methods in computational fluid dynamics. In: NASA Ames Research Center. [S.l.: s.n.], 2005.

ROE, P. Approximate riemann solvers, parameter vectors, and difference schemes. Journal of Computational Physics, 1981. v. 43, p. 357-372, 1981.

SALEEL, C.; SHAIJA, S.; JAYARAJ, S. On simulation of backward facing step flow using immersed boundary method. American Journal of Fluid Dynamics, 2013. v. 3(2), p. 9-19, 2013. DOI: 10.5923/j.ajfd.20130302.01.

THAKUR, S.; WRIGHT, J. A multiblock operatorsplitting algorithm for unsteady flows at all speeds in complex geometries. International Journal for Numerical Methods in Fluids, 2004. v. 31, p. 383-413, 2004. 
THOMPSON, J.; WARSI, Z.; MASTIN, C. Numerical Grid Generation: foundations and applications. 1. ed. [S.1.]: Copyright, 1985.

ZHANG, X.; BLAISDELL, G.; LYRINTZIS, A. Highorder compact schemes with filters on multi-block domains. Journal of Scientific Computing, 2004. v. 21(3), p. 69-354, 2004. 